\title{
Malignant multiple sclerosis: clinical and demographic prognostic factors
}

\author{
Esclerose múltipla maligna: fatores prognósticos clínicos e demográficos \\ Fabrício Hampshire-Araújo', Anke Bergmann², Regina Maria Papais Alvarenga3,4, \\ Cláudia Cristina Ferreira Vasconcelos ${ }^{1}$
}

\begin{abstract}
Patients with malignant multiple sclerosis (MMS) reach a significant level of disability within a short period of time (Expanded Disability Status Scale score of 6 within five years). The clinical profile and progression of the disease were analyzed in a Brazilian cohort of 293 patients. Twenty-five (8,53\%) patients were found to have MMS and were compared with the remaining 268 (91,47\%). Women, non-white patients, older age at disease onset, shorter intervals between the first attacks, and more attacks in the first two years of the disease were all more common in the MMS group. These findings could serve as prognostic factors when making therapeutic decisions.
\end{abstract}

Keywords: multiple sclerosis; disease progression.

\section{RESUMO}

Os doentes com esclerose múltipla maligna (EMM) atingem um nível significativo de incapacidade dentro de um curto período de tempo (EDSS 6 em até 5 anos desde primeiro sintoma/sinal da doença). 0 perfil clínico e progressão da doença foram analisados em uma coorte brasileira de 293 pacientes. Vinte e cinco (8,53\%) pacientes foram encontrados com EMM e foram comparados com os restantes 268 (91,47\%). Mulheres, pacientes não-brancos, idade mais avançada no início da doença, intervalos mais curtos entre os primeiros ataques e, mais ataques nos dois primeiros anos da doença, foram mais comuns no grupo com EMM. Estes achados podem servir como fatores prognósticos na tomada de decisão terapêutica.

Palavras-chave: esclerose múltipla; progressão da doença.

In multiple sclerosis (MS), the clinical course and degree of disability resulting from autoimmune inflammation of the central nervous system and from axonal damage vary ${ }^{1}$, often beginning in the initial phases². Certain patients reach greater degrees of disability within a short period of time. This severe progressive form is referred to as malignant multiple sclerosis (MMS) when an Expanded Disability Status Scale (EDSS) score of 6 is reached within five years of disease onset ${ }^{3,4}$. Early recognition of potentially severe cases based on prognostic factors is crucial when making therapeutic decisions to reduce the risk of disability and impaired quality of life. This study analyzed a cohort of Brazilian patients to identify cases of MMS and potential prognostic factors indicating more severe progression.

\section{METHODS}

This observational study included a retrospective analysis of demographic data and clinical data collected from medical records of 293 MS patients according to McDonald et al criteria ${ }^{5}$. The patients had been regularly followed up at the Hospital Federal da Lagoa in Rio de Janeiro, Brazil. Based on the time to reach EDSS 6, patients were classified as MMS up to five years, or non-malignant-MS (NMMS) after five years. The internal review board of the Gafrée and Guinle Teaching Hospital approved the protocol.

Frequencies, percentages, means and standard deviations were calculated for demographic and clinical variables. To analyze progression, Kaplan-Meier curves were constructed based on the time to reach EDSS 3 and 6 and were

\footnotetext{
${ }^{1}$ Universidade Federal do Estado do Rio de Janeiro, Departamento de Neurologia, Rio de Janeiro RJ, Brasil;

${ }^{2}$ Instituto Nacional de Câncer, Rio de Janeiro RJ, Brasil;

${ }^{3}$ Hospital Federal da Lagoa, Departamento de Neurologia, Rio de Janeiro RJ, Brasil;

${ }^{4}$ Hospital Universitário Gaffree e Guinle, Departamento de Neurologia, Rio de Janeiro RJ, Brasil.

Correspondence: Fabrício Hampshire-Araújo; Universidade Federal do Estado do Rio de Janeiro, Departamento de Neurologia; Rua Mariz e Barros, 775; 22290-240 Rio de Janeiro RJ, Brasil; E-mail: fabhampshire@gmail.com

Conflict of interest: There is no conflict of interest to declare.

Received 08 August 2016; Accepted 21 November 2016.
} 
analyzed by the log-rank test. To compare malignant and non-malignant forms, odds ratios and 95\% confidence intervals were calculated. The Student's t-test was used to analyze the time between the first attacks. Statistical significance was defined as $\mathrm{p}<0.05$.

\section{RESULTS}

Twenty-five patients had MMS (8,53\%). Most were women (52\%) and of African descent (52\%), 64\% of patients were 30 years old or younger at the disease onset. Relapsing remitting MS (RRMS) was more common than the primary-progressive form (PPMS) in NMMS (93.7\% versus 68\%; $\mathrm{p}<0.001$ ), whereas PPMS was more prevalent in MMS (32\% versus 5.2\%; $\mathrm{p}<0.001$ ). There was a non-significant difference between the groups in the mean time from first symptom until diagnosis (4.2 versus 6.0 years).The median time from first symptom until diagnosis was four years for non-malignant form (0.1 to 29 years) and two years for MMS (0.5 to 25 years). Mean time until treatment with disease-modifying drugs was significantly shorter in MMS (4.0 versus 7.7 years; $p=0.025$ ).

Table shows the comparison of the demographic characteristics and clinical progression between groups. Significant differences were found for sex, ethnicity, recovery after the first attack, number of relapses during the first year, and time between the first two attacks.

Regarding the clinical progression, the risk for progression was 10-fold greater for patients with MMS (OR = 14.5; 95\%CI: 4.4-48.1); $35.5 \%$ of MMS patients had reached secondary progression versus 3.6\% in NMMS ( $p<0.001$ ). In MMS, $87 \%$ of patients reached EDSS 3 within three years and $44 \%$ reached EDSS 6 directly, 44\% of patients MMS reached EDSS 6 before 40 years of age versus $7 \%$ of NMMS patients $(p<0.001)$. (This data is not shown in the Table).

The time to reach disability markers was significantly shorter in patients with RRMS classified as MMS compared to those classified as NMMS (EDSS 3: 12 versus 192 months, $\mathrm{p}<0.001$ ) (EDSS 6: 36 versus 324 months; $\mathrm{p}<0.001$ ). The Figure represents time curves to reach EDSS 3 and 6.

\section{DISCUSSION}

The nomenclature and criteria define the more severe progressive forms of MS, although the degree of disability and time to reach disability constitute the principal parameters. In addition to MMS, the term aggressive $M S$ has also been used. The different criteria adopted always include the early disability provoked by frequent attacks and/or progression, and intense inflammatory activity detected by magnetic resonance imaging ${ }^{6}$. The term fulminant MS, although adopted previously, is currently associated with Marburg's variant in which progression is monophasic with inexorable deterioration and rapid death?

Malignant/aggressive forms occur in 4-14\% of cases $^{3,4}$; and this Brazilian cohort, in which $8.5 \%$ of patients developed severe disability within five years, confirmed these data. This percentage includes both RRMS and PPMS; however, if only the former were considered, this rate would fall to $5.8 \%$. In the few studies conducted on malignant/aggressive

Table. Comparison of demographic and clinical characteristics between patients with malignant (MMS) and non-malignant multiple sclerosis (NMMS).

\begin{tabular}{|c|c|c|c|c|}
\hline \multirow{2}{*}{ Characteristics } & MMS (25) & NMMS (268) & \multirow{2}{*}{ OR (95\%Cl) } & \multirow{2}{*}{$p$-value } \\
\hline & $\mathrm{n}(\%)$ & n (\%) & & \\
\hline \multicolumn{5}{|l|}{ Gender } \\
\hline Male & $12(48.0)$ & $59(22.1)$ & 3.27 & \multirow{2}{*}{0.007} \\
\hline Female & $13(52.0)$ & $209(77.9)$ & $(1.42-7.54)$ & \\
\hline \multicolumn{5}{|l|}{ Ethnicity } \\
\hline Non-white & 13(52.0) & $78(29.1)$ & 2.80 & \multirow{2}{*}{0.020} \\
\hline White & $11(44.0)$ & $185(69.0)$ & $(1.2-6.5)$ & \\
\hline \multicolumn{5}{|l|}{ Recovery from the first attack } \\
\hline No & $9(37.5)$ & $11(5.0)$ & 11.5 & \multirow{2}{*}{$<0.001$} \\
\hline Yes & $15(62.5)$ & $211(95.0)$ & $(4.1-32.1)$ & \\
\hline \multicolumn{5}{|l|}{ Number of relapses during $1^{\text {st }}$ year } \\
\hline 2 or more relapses & $10(40.0)$ & $39(14.6)$ & 4,6 & \multirow{2}{*}{0.002} \\
\hline 1 relapse & $11(44.0)$ & $198(73.9)$ & $(1.8-11.6)$ & \\
\hline Time interval between $1^{\text {st }}$ and $2^{\text {nd }}$ attacks & $18(81.8)$ & $140(55.8)$ & 3.6 & \\
\hline$\leq 2$ years & $4(18.2)$ & $111(44.2)$ & $(1.2-10.8)$ & 0.013 \\
\hline$>2$ years & $17(6.4)$ & $3(12.0)$ & & \\
\hline
\end{tabular}

The differences in $n$ correspond to the absence of information. 

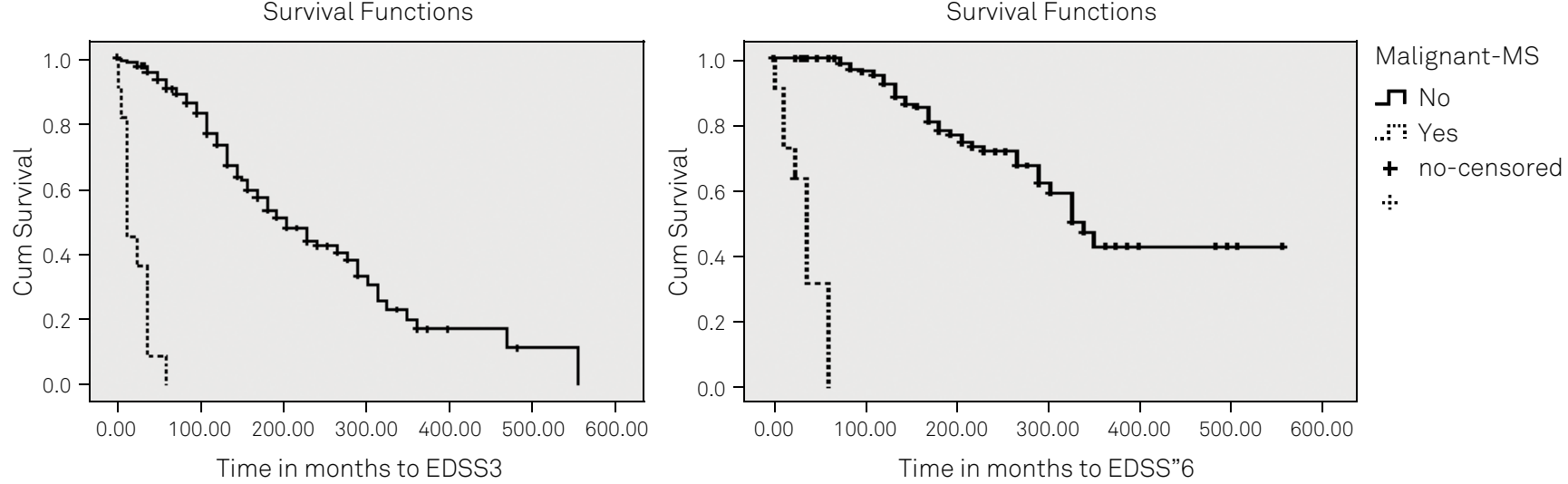

EDSS: Expanded Disability Status Scale; RRMS: Relapsing remitting MS.

Figure. Kaplan Meier curves of time in months to reach EDSS 3 and 6 for RRMS malignant and no malignant.

forms, most patients had RRMS ${ }^{3,4}$. Of the MMS cases in the present study, over half had RRMS.

Including PPMS patients may create a bias, since their progression rate is faster, with these patients reaching EDSS 6 within five years. Gholipour et al. included PPMS patients and reported a frequency of MMS of $78.57 \%^{3}$, while Menon et al. reported $25.57 \%$ of PPMS cases in a group of MMS patients ${ }^{4}$.

Despite the severity, RRMS patients respond to treatment with immunomodulators and immunosuppressant and immunoablative therapy if inflammatory activity is present ${ }^{6}$. Only RRMS patients are included in the progression curves presented here, and the median times until reaching the markers of moderate and severe disability were one and three years respectively, revealing a short period in which there is a viable therapeutic window. Although no consensus exists on the time and degree of disability required to classify MS as severe, EDSS 6 is used as a cut-off point for the implementation of aggressive treatment ${ }^{4}$.
In studies on the natural history of MS, clinical factors have been linked to a more severe prognosis ${ }^{34,8,9,10}$. Many of these factors were observed in the patients classified as MMS in this study. There were significantly more patients of African descent, patients in whom motor symptoms were the first manifestation, a shorter time interval between initial attacks, more patients with a residual deficit from the first attack, more patients with more than one attack in the first year, and more cases of progression right from the onset. Conversely, MMS has been described as being more common in men ${ }^{3,4}$, while in this study more women had MMS. A larger sample population may have achieved different results.

In conclusion, according to the generally accepted concept of MMS, < $10 \%$ of patients in this Brazilian cohort reached severe disability within five years. Identifying demographic and clinical prognostic factors may make early treatment with more effective drugs more feasible.

\section{References}

1. Trapp BD, Peterson J, Ransohoff RM, Rudick R, Mörk S, Bö L. Axonal transection in the lesions of multiple sclerosis. N Engl J Med. 1998;338(5):278-85. https://doi.org/10.1056/NEJM199801293380502

2. Ferguson B, Matyszak MK, Esiri MM, Perry VH. Axonal damage in acute multiple sclerosis lesions. Brain. 1997;120(3):393-9. https://doi.org/10.1093/brain/120.3.393

3. Gholipour T, Healy B, Baruch NF, Weiner HL, Chitnis T. Demographic and clinical characteristics of malignant multiple sclerosis. Neurology. 2011;76(23):1996-2001. https://doi.org/10.1212/WNL.0b013e31821e559d

4. Menon S, Shirani A, Zhao Y, Oger J, Traboulsee A, Freedman MS et al. Characterising aggressive multiple sclerosis.J Neurol Neurosurg Psychiatry. 2013;84(11):1192-8. https://doi.org/10.1136/jnnp-2013-304951

5. Polman CH, Reingold SC, Edan G, Filippi M, Hartung HP, Kappos Let al. Diagnostic criteria for multiple sclerosis: 2005 revisions to the "McDonald Criteria". Ann Neurol. 2005;58(6):840-6. https://doi.org/10.1002/ana.20703
6. Rush CA, MacLean HJ, Freedman MS. Aggressive multiple sclerosis: proposed definition and treatment algorithm. Nat Rev Neurol. 2015;11(7):379-89. https://doi.org/10.1038/nrneurol.2015.8

7. Rahmlow MR, Kantarci O. Fulminant demyelinating diseases. Neurohospitalist. 2013;3(2):81-91. https://doi.org/10.1177/1941874412466873

8. Degenhardt A, Ramagopalan SV, Scalfari A, Ebers GC. Clinical prognostic factors in multiple sclerosis: a natural history review. Nat Rev Neurol. 2009;5(12):672-82. https://doi.org/10.1038/nrneurol.2009.178

9. Scalfari A, Neuhaus A, Degenhardt A, Rice GP, Muraro PA, Daumer $M$ et al. The natural history of multiple sclerosis: a geographically based study 10: relapses and long-term disability. Brain. 2010;133(7):1914-29. https://doi.org/10.1093/brain/awq118

10. Confavreux C, Vukusic S. Natural history of multiple sclerosis: a unifying concept. Brain. 2006;129(3):606-16. https://doi.org/10.1093/brain/awl007 